\title{
EVALUASI URETEROSKOPI DENGAN LASER HOLMIUM: YTTRIUM- ALUMINUM-GARNET UNTUK PENATALAKSANAAN BATU URETER DI RUMAH SAKIT PERSEKUTUAN GEREJA INDONESIA CIKINI TAHUN 2010-2012
}

\author{
Octoveryal Aslim ${ }^{1}$, Pande Made Wisnu Tirtayasa ${ }^{1}$, Adi Bachtiar Tambah ${ }^{2}$, Frendy Wihono ${ }^{2}$, \\ Winner $^{2}$, Egi Edward Manuputty ${ }^{2}$, David Manuputty ${ }^{2}$ \\ ${ }^{1}$ Pendidikan Dokter Spesialis Urologi, Departemen Urologi, Fakultas Kedokteran Universitas Indonesia/Rumah \\ Sakit Umum Pusat Cipto Mangunkusumo, Jakarta, Indonesia. Korespondensi: octoaslim@gmail.com \\ ${ }^{2}$ Divisi Urologi, Departemen Bedah Rumah Sakit Persekutuan Gereja Indonesia, Cikini, Jakarta.
}

\begin{abstract}
ABSTRAK
Tujuan: untuk mengetahui efektivitas ureterorenoscopy (URS) menggunakan laser Holmium: Yttrium-Aluminum-Garnet (Ho: YAG) untuk pengelolaan batu ureter di Rumah Sakit Persekutuan Gereja Indonesia (PGI) Cikini sepanjang tahun 2010 hingga 2012. Metode: data dikumpulkan retrospektif dari catatan medis pasien di Rumah Sakit PGI Cikini dari 1 Januari 2010 sampai 31 Desember 2012 yang menjalani URS dengan Ho: YAG lithotripter laser untuk mengobati penyakit batu saluran kemih. Kriteria inklusi pada semua pasien dengan batu saluran kemih dilakukan URS menggunakan laser Ho: YAG. Hasil: sebanyak 205 penyakit batu ureter dari 182 pasien yang mendapat pengobatan URS dengan Ho: YAG laser litotriptor di Rumah Sakit PGI Cikini, terdiri dari 143 laki-laki dan 39 wanita dengan rata-rata umur 45,69 tahun (19-76). Terdiri dari 115 batu ureter kanan dan 90 kiri, dengan 128 batu ureter proksimal dan 77 distal. Komorbititas yang paling sering muncul adalah hydronephrosis sejumlah 169 (88,5\%) dan 155 (75,6\%) komorbiditas dari kasus lainya. Komplikasi post operatif ditemukan pada 11 pasien (5,8\%). Rata-rata waktu operasi 55,19 menit dan rata-rata lama rawat inap pasien paska operasi adalah 3,31 hari. Angka bebas batu secara keseluruhan adalah 88,3\%. Dimana angka bebas batu pada ureter proksimal adalah 85,9\%, sedangkan ureter distal 89,6\%, dengan angka bebas batu secara keseluruhan yaitu 88,3\%. Simpulan: URS memakai laser Ho: YAG merupakan prosedur yang aman dan efektif untuk pasien dengan batu ureter terlepas dari lokasi batu pada ureter.
\end{abstract}

Kata kunci: batu ureter, ureteroskopi, laser Ho: YAG, hydronephrosis.

EVALUATION OF URETEROSCOPY WITH A HOLMIUM: YTTRIUMALUMINUM-GARNET LASER FOR THE MANAGEMENT OF URETERAL STONES IN CIKINI COMMUNION OF CHURCHES IN INDONESIA HOSPITAL IN 2010-2012

Octoveryal Aslim ${ }^{1}$, Pande Made Wisnu Tirtayasa ${ }^{1}$, Adi Bachtiar Tambah ${ }^{2}$, Frendy Wihono ${ }^{2}$, Winner $^{2}$, Egi Edward Manuputty ${ }^{2}$, David Manuputty ${ }^{2}$

${ }^{1}$ Urology Training Programme, Department of Urology, Faculty of Medicine Indonesia University, Cipto Mangunkusumo National General Hospital, Jakarta.

${ }^{2}$ Urology Division, Department of Surgery, Persekutuan Gereja Indonesia Hospital Cikini, Jakarta.

\section{ABSTRACT}

Objective: to investigate the efficacy of ureterorenoscopy (URS) using a Holmium: YttriumAluminum-Garnet (Ho: YAG) laser for the management of ureteral stone in Cikini Communion of Churches in Indonesia (CCI) Hospital. Methods: data were collected retrospectively from patient's 
medical records in Cikini CCI Hospital from 1 January 2010 till 31 December 2012 who underwent URS with a Ho: YAG laser lithotriptor to treat ureteral stone diseases. The inclusion criteria were all patients with ureteral stone treated by URS using a Ho: YAG laser. Results: as many as 205 ureteral stone diseases from 182 patients were treated by URS with a Ho: YAG laser lithotriptor in Cikini CCI Hospital, they comprised of 143 men and 39 women with the mean age of 45.69 years (19 to 76 ). There were 115 right and 90 left ureteral stones, with 128 proximal versus 77 distal ureteral stones. The most common comorbidity was hydronephrosis up to 169 (88.5\%) and 155 (75.6\%) other comorbidities from all other causes. Post operation complications were found in 11 patients $(5.8 \%)$. Mean operation time was 55.19 minutes and mean post operation hospital stay was 3.31 days. The stone free rates for proximal and distal ureteral stones were $85.9 \%$ and $89.6 \%$ respectively $(\mathrm{p}=0.340$ ), with the overall stone free rates was $88.3 \%$. Conclusion: URS with a Ho: YAG laser is a safe and effective procedure for the management of ureteral stone with high stone free rates irrespective of stone location.

Keywords: ureteral stone, ureteroscopy, Ho: YAG laser, hydronephrosis.

\section{PENDAHULUAN}

Tujuan dari tindakan operasi pada pasien penderita batu ureter adalah untuk membebaskan obstruksi ginjal dan mencapai kondisi bebas batu dengan morbiditas minimal. Terdapat berbagai tatalaksana dalam mengatasi batu ureter, antara lain extracorporeal shock wave lithotripsy (ESWL), ureterorenoscopy (URS) retrograd, litotripsi perkutan secara antegrad, dan ureterolithotomi konvensional maupun laparaskopi. ${ }^{1}$ Tatalaksana optimal bergantung pada beberapa faktor, termasuk ukuran batu, komposisi batu, kondisi klinis pasien, peralatan yang tersedia dan kemampuan operator. $^{2}$ Kemajuan dalam desain ureteroscope, metode baru dalam fragmentasi batu intracorporeal, teknik laparaskopi dan perkembangan ESWL telah merubah modalitas tatalaksana batu ureter. $^{2,3}$

Kemajuan dalam URS telah mengoptimalkan fragmentasi dan angka bebas batu serta menurunkan morbiditas. Oleh karena itu URS litotripsi menjadi pilihan yang sangat baik. ${ }^{4}$ Terdapat empat metode litotripsi intrakorporal antara lain, elektrohidrolik, laser, ultrasonik, dan balistik. Pada awal tahun 1990, metode litotripsi memakai laser Holmium: Yttrium-Aluminum-Gamet (Ho: YAG) ureterolitotripsi diperkenalkan dalam praktek urologi dan terbukti memberikan hasil baik terhadap jaringan lunak dan batu saluran kemih. ${ }^{1,5}$ Adanya laser Ho: YAG telah meningkatkan angka bebas batu dan menurunkan resiko komplikasi sehingga menjadi prosedur pilihan untuk batu ureter yang impacted. ${ }^{1}$

Tujuan dari penelitian ini adalah untuk mengevaluasi peranan ureteroskopi memakai litotriptor laser Ho: YAG sebagai tatalaksana pasien dengan batu ureter di Rumah Sakit Persekutuan Gereja Indonesia (PGI) Cikini sepanjang tahun 2010 hingga 2012.

\section{METODE}

Data dikumpulkan secara retrospektif dari rekam medis pasien yang menjalani prosedur URS memakai Ho: YAG laser untuk mengatasi batu ureter di Rumah Sakit PGI Cikini dari 1 Januari 2010 sampai dengan 31 Desember 2012. Kriteria inklusi meliputi semua pasien 
yang ditatalaksana dengan URS memakai Ho: YAG laser.

Data yang dikumpulkan dari rekam medis termasuk jenis kelamin, usia, sisi ureter, lokasi batu ureter, komorbiditas klinis, operasi simultan lainnya, lama operasi, lama perawatan post operasi, lama $J J$ stent dipertahankan, dan angka bebas batu.

Terminologi ureter proksimal mengacu pada bagian ureter proksimal hingga ke pelvic brim, dan ureter distal dimulai dari pelvic brim hingga kandung kemih.

Definisi bebas batu adalah tidak terdapat batu sisa baik yang retropulsi saat operasi maupun dari pemeriksaan rontgen polos abdomen maupun ultrasonografi ginjal paska operasi.

\section{HASIL}

Terdapat 182 pasien dengan batu ureter yang menjalani URS dengan Ho: YAG laser pada tabel 1.

Tabel 1. Data Demografi Pasien

\begin{tabular}{lc}
\hline Total kasus & 205 \\
Total pasien & 182 \\
Jenis kelamin & \\
$\quad$ pria / wanita & 143 / 39 \\
Rerata usia (range) & 45,69 (19-76) tahun \\
Sisi ureter & \\
$\quad$ kanan / kiri & 115 / 90 \\
Lokasi & \\
$\quad$ proksimal / \\
$\quad$ distal
\end{tabular}

Keseluruhan pasien terdiri dari 143 pria dan 39 wanita, usia rerata adalah 45,69 (19-76) tahun. Empat belas dari 182 pasien menderita batu ureter bilateral dan sembilan pasien menderita batu ureter proksimal bersamaan dengan batu ureter distal pada sisi yang sama, sehingga total kasus menjadi 205 prosedur URS. Kasus terdiri dari 115 batu ureter kanan dan 90 batu ureter kiri, dengan 128 batu ureter proksimal, dan 77 batu ureter distal.

Komorbiditas pasien, operasi simultan, komplikasi, lama operasi, lama perawatan post operasi, lama $J J$ stent dipertahankan, dan kondisi bebas batu tampak pada tabel 2.

Tabel 2. Komorbiditas pasien, operasi simultan, komplikasi, lama operasi, dan lama perawatan

\begin{tabular}{lc}
\hline Hidronefrosis / kasus & $169(82,4 \%)$ \\
Komorbiditas / kasus & $155(75,6 \%)$ \\
Operasi simultan & $33(16,1 \%)$ \\
Komplikasi & $11(5,4 \%)$ \\
Rerata lama operasi & 55,19 \\
$\quad$ (range) menit & $(15-235)$ \\
Lama perawatan & 3,31 \\
$\quad$ post operation & $(0-22)$ \\
$\quad$ range $)$ hari & \\
Lama $J J$ stent & \\
dipertahankan & $(2-167)$ \\
$\quad$ range $)$ hari & \\
Kondisi bebas batu & \\
-Keseluruhan & $181(88,29 \%)$ \\
-Batu ureter & \\
$\quad$ proksimal & $110(85,9 \%)$ \\
$\quad(n=128)$ & \\
-Batu ureter distal & $69(89,6 \%)$ \\
\hline
\end{tabular}

Komorbiditas terbanyak adalah Hidronefrosis, yaitu $169(82,4 \%)$ dari 205 kasus, terdapat $155 \quad(75,6 \%)$ kelainan penyerta pada keseluruhan kasus. Kelainan penyerta lainnya meliputi hidroureter ipsilateral (102 pasien), batu ginjal kontralateral (12 pasien), batu ginjal ipsilateral (20 pasien), stenosis ureter kontralateral (3 pasien), stenosis ureter ipsilateral (7 pasien), batu cetak ginjal kontralateral (3 pasien), kingking ureter ipsilateral (4 pasien), kinking ureter 
konralateral (1 pasien), batu kandung kemih (2 pasien), dan pembesaran prostat jinak (1 pasien).

Operasi simultan lain dilakukan pada 33 pasien $(16,1 \%)$, operasi-operasi tersebut adalah extended pielolitotomi kontralateral dan insersi $J J$ stent (3 pasien), ESWL pada batu ginjal ipsilateral (14 pasien), URS lasertripsi kontralateral (10 pasien), insersi JJ stent kontralateral (3 pasien), lasertripsi batu kandung kemih (2 pasien), dan laser prostatektomi (1 pasien).

Terdapat 11 pasien yang mengalami demam setelah operasi $(5,4 \%)$ yang diobati dengan antibiotik intravena Kami melakukan insersi JJ stent pada tiap kasus yang dipertahankan rerata selama 33,2 hari. Tidak terdapat konversi open selama tindakan.

Pada tabel 3, angka bebas batu secara keseluruhan adalah $88,29 \%$, yang mana angka bebas batu pada ureter proksimal adalah $85,9 \%$, sedangkan ureter distal 89,6\%. Kami melakukan tindakan ESWL untuk tatalaksana batu sisa.

Table 3. Analisis angka bebas batu

\begin{tabular}{cccc}
\hline Lokasi & \multicolumn{2}{c}{ Bebas batu } & \\
\cline { 2 - 3 } batu di & Yes & No & p \\
ureter & & & \\
\hline Proksimal & 110 & 18 & \\
$(\mathrm{n}=128)$ & $(85,9 \%)$ & $(14,0 \%)$ & $0,340^{*}$ \\
$\begin{array}{c}\text { Distal } \\
(\mathrm{n}=77)\end{array}$ & 69 & 8 & \\
\hline
\end{tabular}

*Uji Chi-Square

\section{DISKUSI}

Laser Holmium: YAG telah menunjukkan hasil yang sangat baik dalam penatalaksanaan endoskopi pada batu ureter dengan kisaran angka bebas batu antara $80 \%$ dan $100 \% .^{1,2,6-11}$ Penelitian kami menunjukkan angka bebas batu secara keseluruhan adalah 88,3\%.
Kelebihan dari laser Ho: YAG dibandingkan dengan perangkat litotriptor lainnya terletak pada kecilnya ukuran instrument dan kemampuan fragmentasi yang sangat baik terhadap batu terlepas dari komposisinya. ${ }^{1}$ Panjang gelombang laser sebesar $2.100 \mathrm{~nm}$ yang diserap air dihantarkan pada jaringan dan permukaan batu akan menghasilkan kemampuan memotong dan ablasi jaringan yang sangat baik. Laser Ho: YAG dapat menghancurkan batu menjadi fragmen yang lebih halus dibandingkan dengan alat litotriptor lainnya, sehingga sesuai untuk batu ureter yang besar tanpa memerlukan penggunaan basket maupun forceps. ${ }^{12}$ Disintegrasi total dapat mengurangi keluar masuknya alat melalui muara ureter sehingga dapat mengurangi lama operasi. Laser Ho: YAG merupakan litotriptor ideal untuk batu ureter yang besar. Penelitian sebelumnya menunjukkan bahwa ukuran batu tidak mempengaruhi angka bebas batu pada batu ureter. ${ }^{1,2,13}$

Menurut Seitz et al, komorbiditas terbanyak pada batu ureter adalah hidronefrosis mencapai $85,3 \% .^{1}$ Pada penelitian kami menemukan $82,4 \%$ mengalami hidronefrosis dari keseluruhan kasus. Penelitian sebelumnya melaporkan komplikasi post operasi berkisar antara 1,3\% sampai $7 \%$. ${ }^{1}$ Dalam penelitian kami ditemukan $5,4 \%$ kasus mengalami komplikasi post operasi setelah menjalani URS dengan laser Ho: YAG.

Pasien yang mengalami batu ureter yang impacted, dinding ureter dapat mengalami inflamasi yang disertai edema, fibrosis interstisial, dan hipertrofi urotelial pada stone bed. ${ }^{1}$ Hal-hal tersebut dapat menghambat disintergrasi batu dan meningkatkan resiko kerusakan dinding ureter karena reaksi inflamasi batu yang akan menyebabkan iskemi. Disintegrasi 
batu ureter yang impacted dapat dilakukan memakai laser Ho: YAG sebagai litotriptor.

Perkembangan instrument dan teknik URS telah menurunkan insidensi komplikasi. Avulsi ureter komplit adalah salah satu komplikasi yang paling serius saat melakukan URS, hal ini hampir selalu membutuhkan konversi menjadi operasi terbuka. Stoller dan Wolf's melakukan review pada 33 penelitian sepanjang 1984 hingga 1992 dan mendapatkan 17 (0,3\%) kejadian dalam 5.117 pasien. ${ }^{14}$ Intususepsi ureter merupakan komplikasi yang jarang terjadi, hal ini terjadi invaginasi mukosa ureter akibat traksi lumen ureter yang mengalami kerusakan sirkumferensial parsial. Perforasi ureter adalah komplikasi dari URS yang paling sering dilaporkan. Secara keseluruhan kejadian perforasi ureter telah mengalami penurunan seiring waktu, hal ini disebabkan karena ukuran ureteroscope yang semakin ramping dan peningkatan batas keamanan laser dan perangkat litotripsi pneumatik dibandingseri electrohydraulic lithotripsy sebelumnya. $^{2}$

Untuk menghindari perforasi ureter, penting untuk selalu secara visual mengidentifikasi ujung laser dan sinar penanda selama disintegrasi, terutama bila terdapat kesulitan akses menuju batu. Jarak antara ujung laser dan mukosa saluran kemih harus $>1 \mathrm{~mm}$ untuk menghindari perforasi ureter. ${ }^{1,15}$ Pada tulisan sebelumnya dikatakan bahwa thermal injury pada kedalaman 0,5 dan $1 \mathrm{~mm}$ dapat mengurangi resiko perforasi ureter dan kemunginan stenosis. ${ }^{5}$ Abrasi mukosa dapat terjadi karena gesekan mekanis terhadap epitel transisional ureter selama tindakan URS, mengakibatkan mukosa berdarah maupun edema sehingga visualisasi dan manuver menjadi sulit.
Francesca et al. melaporkan $24 \%$ insiden cedera ureter pada 248 prosedur URS ukuran besar (9,5 atau 11,5 Fr) sedangkan pada instrument yang lebih kecil (6-7,5 Fr) hanya $6 \%$ pada 49 prosedur. $^{14}$ Banyak penelitian telah membuktikan efikasi dan keamanan dari Ho: YAG pada pasien resiko tinggi, seperti pasien anak-anak, wanita hamil ataupun pasien koagulopati dengan urolitiasis. ${ }^{16-19}$

Penelitian sebelumnya melaporkan rerata lama operasi pada batu kurang dari $100 \mathrm{~mm}$ dan lebih dari $10 \mathrm{~mm}$ adalah 34,6 dan 48,2 menit. ${ }^{10}$ Penelitian kami menunjukkan rerata lama operasi adalah 55,2 menit tanpa membedakan ukuran batu.

Komplikasi jangka panjang paska operasi yang paling sering adalah stenosis ureter. Hal ini dapat disebabkan oleh trauma ureter dari instrumentasi batu yang impacted. Penggunaan ureteroskop ukuran besar (9,5-12,5 Fr) juga dapat menyebabkan stenosis karena trauma mukosa ureter. Angka kejadian stenosis telah mengalami penurunan seiring dengan ukuran ureteroskop yang semakin ramping dan teknik ureteroskopi yang semakin baik.

Beberapa instrumen tambahan telah tersedia untuk meningkatkan keberhasilan dari URS litotripsi. Kegagalan URS litotripsi pada batu ureter proksimal sering disebabkan oleh migrasi batu ke dalam pelvis renalis dan kalises. Perangkat Basket diproduksi dari material yang sangat fleksibel (nitinol) dengan ukuran cukup kecil untuk mengurangi impedansi aliran irrigant melalui working channel URS sehingga meningkatkan visualisasi. Ho: YAG laser juga sangat meningkatkan efektivitas litotripsi intracorporal. ${ }^{2}$ Berbagai perangkat telah dikembangkan 
untuk mencegah migrasi batu selama litotripsi, seperti stone cone. ,20 $^{2,2}$

Pada penelitian kami, semua kasus paska litotripsi dilakukan insersi JJ stent untuk mencegah obstruksi karena edema mukosa ureter paska tindakan.

\section{SIMPULAN}

URS memakai laser Ho: YAG merupakan prosedur yang aman dan efektif untuk pasien dengan batu ureter terlepas dari lokasi batu pada ureter.

\section{DAFTAR PUSTAKA}

1. Seitz C, Tanovic E, Kikic Z, et al. Impact of stone size, location, composition, impaction, and hydronephrosis on the efficacy of holmium: YAG-laser ureterolithotripsy. Eur Urol. 2007;52:1751-9.

2. Kijvikai K, Haleblian GE, Preminger GM, et al. Shock wave lithotripsy or ureteroscopy for the management of proximal ureteral calculi: an old discussion revisited. $J$ Urol. 2007;178:1157-63.

3. Anagnostou T, Tolley D. Management of ureteric stones. Eur Urol. 2004;45:714-21.

4. Bierkens AF, Hendrikx AJM, de la Rosette JJMCH, et al. Treatment of mid- and lower ureteric calculi: extracorporeal shock-wave lithotripsy vs laser ureteroscopy. A comparison of costs, morbidity, and effectiveness. $\mathrm{Br}$ J Urol. 1998;81:31-5.

5. Johnson DE, Cromeens DM, Price RE. Use of the Ho: YAG in urology. Lasers Surg Med. 1992;12:353-63.

6. Salem HK. A prospective randomized study comparing shock wave lithotripsy and semirigid ureteroscopy for the management of proximal ureteral calculi. Urology. 2009;74:1216-22.

7. Teichman JM, Rao RD, Rogenes VJ, et al. Ureterorenoscopic management of ureteral calculi: electrohydraulic versus holmium: YAG lithotripsy. $J$ Urol. 1997;158:1357-61.

8. Grasso M. Experience with the holmium laser as an endoscopic lithotrite. Urology. 1996;48:199-206.

9. Sofer M, Watterson JD, Wollin TA, et al. Ho: YAG lithotripsy for upper urinary tract calculi in 598 patients. $J$ Urol. 2002;167:31-4.

10. Lam JS, Greene TD, Gupta M. Treatment of proximal ureteral calculi: holmium: YAG laser ureterolithotripsy versus extracorporeal shock wave lithotripsy. J Urol. 2002;167:92.

11. Mediana E, Manuputty EE, Manuputty D. Impact of stone size, stone location, hydronephrosis, and ureteral stenosis on the efficacy of holmium: YAG laser ureterolithotripsy. Unpublished article 2011.

12. Teichman JM, Vassar GJ, Bishoff JT, et al. Holmium: YAG lithotripsy yields smaller fragments than lithoclast, pulsed dye laser or electrohydraulic lithotripsy. J Urol. 1998;159:17-23.

13. Chen CS. Holmium: YAG lasertripsy with semirigid ureterorenoscope for upper-ureteral stones $>2 \mathrm{~cm}$. $J$ Endourol. 2005;19:780-4.

14. Johnson DB, Pearle MS. Complication of ureteroscopy. Urol Clin $N \mathrm{Am}$. 2004:31:157-71.

15. Teichman JM, Vassar GJ, Glickman RD, et al. Holmium: YAG lithotripsy: Photodermal mechanism converts uric acid to cyanide. J Urol. 1998;160:3204. 
16. Minevich E, Sheldon CA. The role of ureterolithotripsy in pediatric urology. Curr Opin Urol. 2006;16:295-8.

17. Wollin TA, Teichman JM, Rogenes VJ, et al. Holmium: YAG lithotripsy in children. J Urol. 1999;162:1717-20.

18. Watterson JD, Girvan AR, Beiko DT, et al. Ureterolithotripsy and holmium: YAG laser lithotripsy: an emerging definitive management strategy for symptomatic ureteral calculi in pregnancy. Urology. 2002;60:383-7.

19. Matsuoka K, Iida S, Inoue $\mathrm{M}$, et al. Endoscopic lithotripsy with the holmium: YAG laser. Lasers Surg Med. 1999;25:389-95.

20. Desai MR, Patel SB, Desai MM, et al. The Dretler stone cone: a device to prevent ureteral stone migration-the initial clinical experience. $J$ Urol. 2002;167:1985-8. 